\title{
3-Methyl-1-butanol production in Escherichia coli: random mutagenesis and two-phase fermentation
}

\author{
Michael R. Connor • Anthony F. Cann • James C. Liao
}

Received: 30 October 2009/Revised: 2 December 2009/Accepted: 4 December 2009/Published online: 14 January 2010

(C) The Author(s) 2010. This article is published with open access at Springerlink.com

\begin{abstract}
Interest in producing biofuels from renewable sources has escalated due to energy and environmental concerns. Recently, the production of higher chain alcohols from 2-keto acid pathways has shown significant progress. In this paper, we demonstrate a mutagenesis approach in developing a strain of Escherichia coli for the production of 3-methyl-1-butanol by leveraging selective pressure toward L-leucine biosynthesis and screening for increased alcohol production. Random mutagenesis and selection with 4-aza-D,L-leucine, a structural analogue to L-leucine, resulted in the development of a new strain of E. coli able to produce $4.4 \mathrm{~g} / \mathrm{L}$ of 3-methyl-1-butanol. Investigation of the host's sensitivity to 3-methyl-1-butanol directed development of a two-phase fermentation process in which titers reached $9.5 \mathrm{~g} / \mathrm{L}$ of 3-methyl-1-butanol with a yield of $0.11 \mathrm{~g} / \mathrm{g}$ glucose after $60 \mathrm{~h}$.
\end{abstract}

Keywords Biofuels · Metabolic engineering ·

Higher alcohols

\section{Introduction}

Growing concerns with the diminishing reserves, supply security, and environmental impact of petroleum-based liquid fuels have intensified efforts to meet these challenges

M. R. Connor · A. F. Cann · J. C. Liao ( $₫)$

Department of Chemical and Biomolecular Engineering,

University of California,

Los Angeles, CA 90095, USA

e-mail: liaoj@seas.ucla.edu
(Connor and Liao 2009; Dinneen 2008; Stephanopoulos 2007). Biofuels produced from renewable sources have the potential to mitigate some of these issues. The production of ethanol, in particular, has steadily risen to 9.2 billion gallons in 2008 in the USA (Seiferlein 2009), with new research directed toward using lignocellulosic feedstocks as a raw material as this would greatly increase the land yield for production and reduce the dependence of fuel production on food crops. Bioethanol production is an attractive option because of the high productivity and yield during fermentation. Ethanol, however, is limited by its low energy density ( $\sim 70 \%$ of gasoline) and hygroscopicity, making it incompatible with the current infrastructure. In hopes of addressing some of the shortcomings of ethanol, potential alternative fuels such as higher chain alcohols produced through the keto acid pathways (Atsumi et al. 2008a, b; Cann and Liao 2008; Connor and Liao 2008; Shen and Liao 2008; Zhang et al. 2008) or through engineered and natural fermentative pathways (Atsumi et al. 2008b; Lee et al. 2008) have been investigated. Higher chain alcohols $(\mathrm{C} 3-\mathrm{C} 5)$, in particular, are attractive fuel alternatives due to their increased energy density and low hygroscopicity.

Previously, a metabolic engineering approach was applied to Escherichia coli for the production of the potential biofuel 3-methyl-1-butanol (3MB; Connor and Liao 2008). Metabolic engineering is the practice by which the development of biological processes is optimized through genetic and regulatory manipulations. This approach has been used for many years in the design of microorganisms for the production of many valuable metabolites and commodity chemicals and, more recently, biofuels (Atsumi et al. 2008a, b; Atsumi and Liao 2008; Kim et al. 2007; Lee et al. 2009; Withers et al. 2007; Yan 
and Liao 2009; Zhang et al. 2008). The use of rational design in the development of a biocatalyst, although widely successful, suffers from a few shortcomings, the most significant being that the metabolic pathway for the production of the target must be elucidated. For effective optimization, details on the genes and enzymes responsible for the synthesis of the target compound, as well as undesired side products, must be known. Cellular metabolism is very complex and often highly interdependent, and it is therefore difficult to account for every detail when designing a strain in this manner. One way to address this concern is to create a random library of strain variants and use selective pressure to discover strains with the desired phenotype. The use of selective pressure can allow for investigation on the order of $10^{9}-10^{12}$ strains, which would not be possible otherwise. This procedure can also be used iteratively to develop strains with increasingly desirable phenotypes. The difficulty in using this strategy is the development of a selection as this is not possible for every process. However, because the production of $3 \mathrm{MB}$ uses the 2-keto acid pathways, the development of a new strain can be greatly aided by the vast knowledge and technology base in amino acid production.

A powerful tool used in the development of amino acid production strains is random mutagenesis and selection with an amino acid analogue (Ikeda 2003). Chemical mutagens such as $N$-methyl- $N$ '-nitro- $N$-nitrosoguanidine (NTG) or ethyl methanesulfonate are often used to create genome-wide mutations, with NTG being the more popular choice due to its superior mutation rate. Selection pressure in this case is provided by the toxicity of amino acid analogues. This toxicity could be due to several effects, including interference in the regulation of amino acid biosynthesis and incorporation into polypeptides. Among the means with which a cell can adapt to survive the challenge of the analogue is the ability to produce the natural amino acid in high enough quantities to outcompete the analogue for incorporation into growing polypeptides. Because this is not the only reason a cell can gain resistance to an analogue, variant strains which show an increased resistance to the amino acid analogue must then be screened and verified for the desired phenotype before being subjected to additional rounds of mutagenesis, if so desired. The advantage of this strategy is that the nearly infinite possibility of created phenotypes can effectively be studied because a selective strategy is being used. This strategy was applied to the production of $3 \mathrm{MB}$ which exploits the L-leucine biosynthesis pathway (Fig. 1). Here, we demonstrate the development of a strain of $E$. coli for the production of $3 \mathrm{MB}$ by subjecting a wild-type strain to mutagenesis by NTG and challenging these cells with 4-aza-D,L-leucine (AZL), a structural analogue to natural L-leucine (Table 1).

\section{Materials and methods}

Bacteria strains, media, and growth conditions JCL16 ( $r r n B_{\mathrm{T} 14}$ $\Delta l a c Z_{\mathrm{WJ} 16} h s d R 514 \quad \Delta \operatorname{araBAD} \mathrm{AH}_{\mathrm{A} 33} \quad \Delta r h a B A D_{\mathrm{LD} 78} / \mathrm{F}^{\prime}$ [traD36, proAB+, lacIq $Z \Delta M 15]$ ) was used as wild type (WT; Table 2).

To compare JCL16, AL1, and AL2 (Table 2), strains were grown in M9 medium $\left(6 \mathrm{~g} \mathrm{Na}_{2} \mathrm{HPO}_{4}, 3 \mathrm{~g} \mathrm{KH}_{2} \mathrm{PO}_{4}\right.$, $1 \mathrm{~g} \mathrm{NH}_{4} \mathrm{Cl}, 0.5 \mathrm{~g} \mathrm{NaCl}, 1 \mathrm{mM} \mathrm{MgSO} 4,1 \mathrm{mM} \mathrm{CaCl}$, $10 \mathrm{mg}$ vitamin $\mathrm{B} 1$ per liter of water) containing $40 \mathrm{~g} / \mathrm{L}$ of glucose, $5 \mathrm{~g} / \mathrm{L}$ of yeast extract, and 1000X A5 trace metals $\operatorname{mix}\left(2.86 \mathrm{~g} \mathrm{H}_{3} \mathrm{BO}_{3}, 1.81 \mathrm{~g} \mathrm{MnCl}_{2} \cdot 4 \mathrm{H}_{2} \mathrm{O}, 0.222 \mathrm{~g}\right.$ $\mathrm{ZnSO}_{4} \cdot 7 \mathrm{H}_{2} \mathrm{O}, \quad 0.39$ g $\mathrm{Na}_{2} \mathrm{MoO}_{4} \cdot 2 \mathrm{H}_{2} \mathrm{O}, 0.079 \mathrm{~g}$ $\mathrm{CuSO}_{4} \cdot 5 \mathrm{H}_{2} \mathrm{O}$, and $49.4 \mathrm{mg} \mathrm{Co}\left(\mathrm{NO}_{3}\right)_{2} \cdot 6 \mathrm{H}_{2} \mathrm{O}$ per liter water). From a $3 \mathrm{~mL}$ Luria-Bertani (LB) overnight, cultures were inoculated $1 \%$ by volume $(v / v)$ into $20 \mathrm{~mL}$ of fresh medium in $250-\mathrm{mL}$ screw cap flasks and grown at $37^{\circ} \mathrm{C}$ in a rotary shaker until the $\mathrm{OD}_{600}$ reached 0.4-0.8. The culture was then induced with $1 \mathrm{mM}$ isopropyl- $\beta$-D-thiogalactopyranoside (IPTG) and grown at $30^{\circ} \mathrm{C}$ for the remainder of the experiment. Antibiotics were added to all cultures (ampicillin $100 \mu \mathrm{g} / \mathrm{mL}$, chloroamphenicol $35 \mu \mathrm{g} / \mathrm{mL}$, and kanamycin $50 \mu \mathrm{g} / \mathrm{mL}$ ).

For production experiments with AL2, $3 \mathrm{~mL}$ LB overnight cultures were used to inoculate $10 \mathrm{~mL}(1 \%, v / v)$ of M9 medium containing $85 \mathrm{~g} / \mathrm{L}$ of glucose, $10 \mathrm{~g} / \mathrm{L}$ of yeast extract, and 1000X A5 trace metals mix and were inoculated $1 \%$ from a $3 \mathrm{~mL}$ LB overnight into a $250-\mathrm{mL}$ screw cap flask. Ten milliliters of oleyl alcohol was added to flasks prior to incubation for extraction experiments. Cultures were grown at $37^{\circ} \mathrm{C}$ in a rotary shaker until the $\mathrm{OD}_{600}$ reached $0.4-0.8$ and were then induced with $1 \mathrm{mM}$ IPTG and incubated at $30^{\circ} \mathrm{C}$ in a rotary shaker. For extraction experiments, equal volumes of the oil and aqueous layers were always sampled to maintain the volume ratio. Antibiotics were added to all cultures (ampicillin $100 \mu \mathrm{g} / \mathrm{mL}$, chloroamphenicol $35 \mu \mathrm{g} / \mathrm{mL}$, and kanamycin $50 \mu \mathrm{g} / \mathrm{mL}$ ).

To determine the viable cell count of AL2 after exposure to $3 \mathrm{MB}$, a $3 \mathrm{~mL} \mathrm{LB}$ overnight was used to inoculate $100 \mathrm{~mL}$ $(1 \%, v / v)$ of M9 medium containing $85 \mathrm{~g} / \mathrm{L}$ of glucose, $10 \mathrm{~g} / \mathrm{L}$ of yeast extract, and 1000X A5 trace metals mix into two $500-\mathrm{mL}$ baffled shake flasks $(50 \mathrm{~mL}$ each). Cultures were grown at $30^{\circ} \mathrm{C}$ in a rotary shaker until the $\mathrm{OD}_{600}$ was $0.4-0.8$ and then split into $15-\mathrm{mL}$ screw cap tubes containing $4 \mathrm{~mL}$ each. $3 \mathrm{MB}$ was then added to the tubes in various concentrations and incubated at $30^{\circ} \mathrm{C}$ in a rotary shaker. Each $3 \mathrm{MB}$ concentration was tested in duplicate tubes. Samples were taken at 8 and $24 \mathrm{~h}$ in which cultures were diluted in triplicate between $10^{-5}$ and $10^{-6}$ and plated on LB agar plates and incubated overnight at $37^{\circ} \mathrm{C}$. The viable cell count was measured by counting the colony forming units (CFU) on each plate and normalizing it to the control $(0 \mathrm{~g} / \mathrm{L} 3 \mathrm{MB})$. 
Fig. 1 Metabolic pathway for amino acid biosynthesis and 3-methyl-1-butanol production. All genes are from $E$. coli unless otherwise noted. BS B. subtilis, LL L. lactis, SC S. cerevisiae

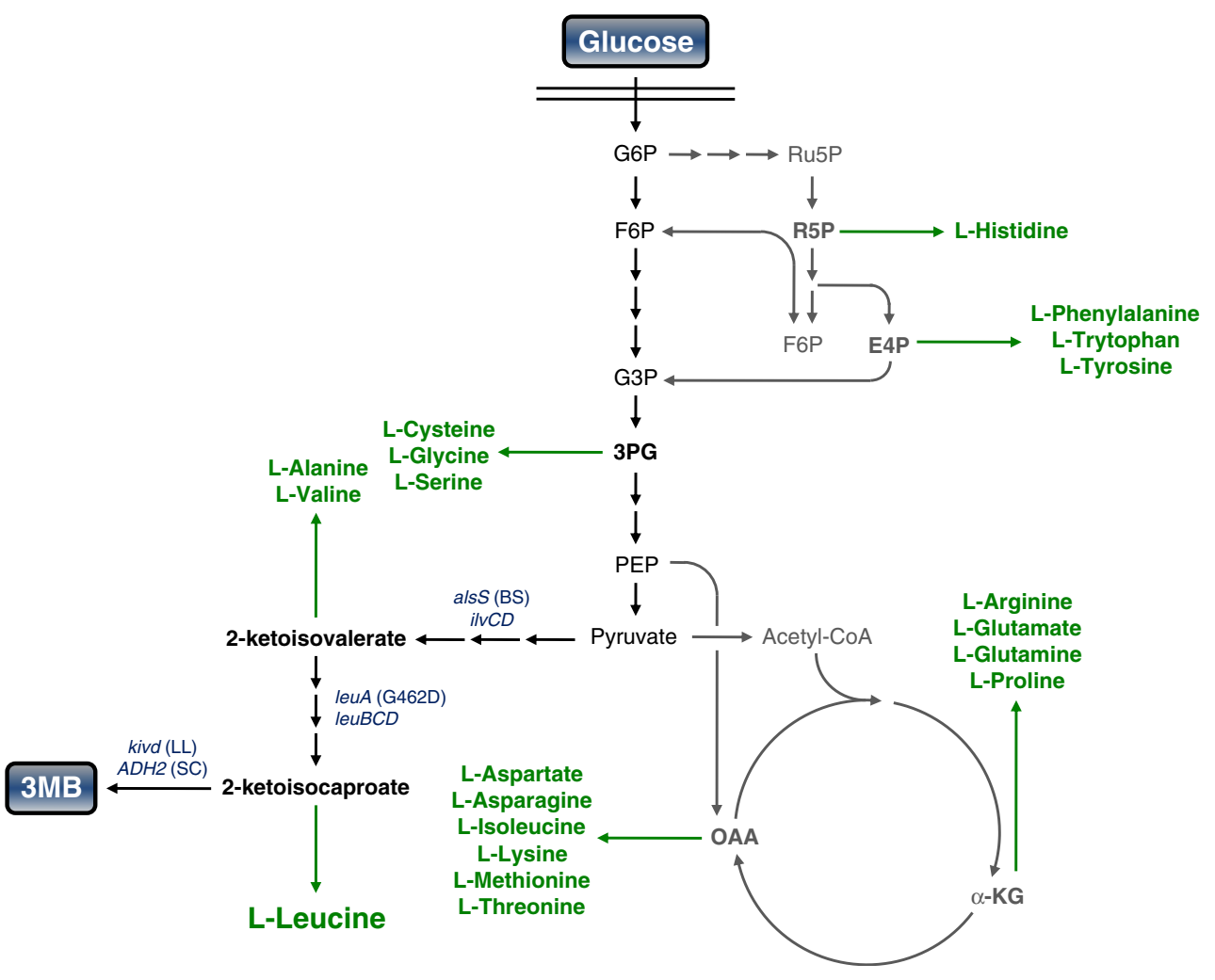

Reagents NTG and AZL were purchased from SigmaAldrich (St. Louis, MO, USA). Alcohol standards were purchased from Fisher Scientific (Pittsburgh, PA, USA) and Sigma-Aldrich. Oleyl alcohol was purchased from Sigma-Aldrich. High-performance liquid chromatography (HPLC) grade heptane was purchased from Fisher Scientific.

Mutagenesis, selection, and screening of mutant libraries The protocol for NTG mutagenesis was adapted from the method of Miller (1972). From $3 \mathrm{~mL}$ LB overnight cultures of the parental strains (JCL16, AL1), cultures were inoculated $1 \%(v / v)$ into $5 \mathrm{~mL}$ of fresh LB medium and grown at $37^{\circ} \mathrm{C}$ in a rotary shaker until the $\mathrm{OD}_{600}$ reached 0.4-0.6. Cells were spun down at room temperature and washed with an equal volume $0.1 \mathrm{M} \mathrm{Na}$ citrate $(\mathrm{pH} 5.5)$ twice before resuspending the cells in half the original volume of $0.1 \mathrm{M} \mathrm{Na}$ citrate. NTG was added to a final concentration of $50 \mu \mathrm{g} / \mathrm{mL}$ from a $1 \mathrm{mg} / \mathrm{mL}$ stock in $0.1 \mathrm{M}$ $\mathrm{Na}$ citrate and incubated at $37^{\circ} \mathrm{C}$ for $15 \mathrm{~min}$. For the control experiment, an equal volume of $0.1 \mathrm{M} \mathrm{Na}$ citrate was added instead of NTG and incubated at $37^{\circ} \mathrm{C}$ for $15 \mathrm{~min}$. After incubation, cells were washed twice with the original volume of $0.1 \mathrm{M}$ phosphate buffer $(\mathrm{pH}$ 7.1). The cells were then resuspended in $5 \mathrm{~mL}$ of $\mathrm{LB}$ and incubated at $37^{\circ} \mathrm{C}$ overnight for outgrowth. A small amount of cells were plated for both the NTG-treated tube and the control tube on LB plates to determine the kill count for the experiment before outgrowth (Table 3). After outgrowth overnight, cultures were spun down and resuspended in $0.1 \mathrm{M}$ phosphate buffer ( $\mathrm{pH}$ 7.1) and plated on M9 plates containing $10 \mathrm{~g} / \mathrm{L}$ of glucose, 1000X A5 trace metals, and $2 \mathrm{~g} / \mathrm{L}$ (JCL16 mutagenesis) or $8 \mathrm{~g} / \mathrm{L}$ (AL1 mutagenesis) of AZL and incubated at $37^{\circ} \mathrm{C}$ for $2-3$ days.

Mutant colonies resistant to AZL were then re-streaked on identical plates to assure a stable phenotype. Colonies with this stable phenotype were then picked and used to inoculate $400 \mu \mathrm{L}$ of $\mathrm{M} 9$ medium containing $10 \mathrm{~g} / \mathrm{L}$ of glucose, $1000 \mathrm{X}$ A5 trace metals, and $1 \mathrm{~g} / \mathrm{L}$ (JCL16 mutagenesis) or $6 \mathrm{~g} / \mathrm{L}$ (AL1 mutagenesis) of AZL in 96-deep-well plates (Corning Inc., Corning, NY, USA). Plates were quantified for growth after $24 \mathrm{~h}$ of incubation at $37^{\circ} \mathrm{C}$ in a rotary shaker.

Mutant strains showing increased growth were then transformed with pIAA12 (Table 2) to screen for $3 \mathrm{MB}$ production. $3 \mathrm{~mL}$ LB overnight cultures of transformant strains were used to inoculate $10 \mathrm{~mL}(1 \%, v / v)$ of $\mathrm{M} 9$ medium containing $10 \mathrm{~g} / \mathrm{L}$ of glucose, $5 \mathrm{~g} / \mathrm{L}$ of yeast extract, and 1000X A5 trace metals in a $125-\mathrm{mL}$ screw cap flask and incubated at $37^{\circ} \mathrm{C}$ in a rotary shaker until the $\mathrm{OD}_{600}$ was $0.4-0.8$. Cultures were then induced with $1 \mathrm{mM}$ IPTG and incubated at $30^{\circ} \mathrm{C}$ in a rotary shaker and sampled at $24 \mathrm{~h}$ for growth and alcohol production. Ampicillin $(100 \mu \mathrm{g} / \mathrm{mL})$ was added to all cultures.

Variant strains showing increased production of $3 \mathrm{MB}$ relative to the parental strain were then transformed with pIAA11, pIAA13, and pIAA16 (Table 2). Three milliliters 
Table 1 Common analogues for branched-chain amino acids

(S)-2-methyl-1-butanol

LB overnights of these strains were used to inoculate $20 \mathrm{~mL}(1 \%, v / v)$ of $\mathrm{M} 9$ medium containing $30 \mathrm{~g} / \mathrm{L}$ of glucose, $5 \mathrm{~g} / \mathrm{L}$ of yeast extract, and 1000X A5 trace metals in a $250-\mathrm{mL}$ screw cap flask and incubated at $37^{\circ} \mathrm{C}$ in a rotary shaker until the $\mathrm{OD}_{600}$ reached $0.4-0.8$. Cultures were induced with $1 \mathrm{mM}$ IPTG and incubated at $30^{\circ} \mathrm{C}$ in a rotary shaker and sampled at 24 and $48 \mathrm{~h}$ for growth and alcohol production. Antibiotics were added to all cultures

Table 2 Strains and plasmids used in this study

\begin{tabular}{|c|c|c|}
\hline Name & Relevant genotype & Reference \\
\hline \multicolumn{3}{|l|}{ Strains } \\
\hline JCL16 & BW25113/F' [traD36, proAB+, lacIq Z $\Delta M 15]$ & Atsumi et al. $2008 \mathrm{~b}$ \\
\hline AL1 & NTG-created mutant from JCL16 & This Study \\
\hline AL2 & NTG-created mutant from AL1 & This study \\
\hline \multicolumn{3}{|l|}{ Plasmids } \\
\hline pIAA11 & pSC101; $\operatorname{Kan}^{\mathrm{R}} ; \mathrm{P}_{\text {LlacO-1 }}:$ alsS $(\mathrm{BS})-i l v C D(\mathrm{EC})$ & Connor and Liao 2008 \\
\hline pIAA12 & ColE1 ; Amp ${ }^{\mathrm{R}} ; \mathrm{P}_{\text {Llaco-1 }}:$ kivd (LL)-ADH2 (SC) ; $\mathrm{P}_{\mathrm{Amp}}:$ bla-lacI (EC) & Connor and Liao 2008 \\
\hline pIAA13 & $\mathrm{p} 15 \mathrm{~A} ; \mathrm{Amp}^{\mathrm{R}} ; \mathrm{P}_{\mathrm{LlacO}-1}: \operatorname{kivd}(\mathrm{LL})-A D H 2(\mathrm{SC})$ & Connor and Liao 2008 \\
\hline pIAA16 & ColE1; $\mathrm{Cm}^{\mathrm{R}} ; \mathrm{P}_{\text {Llaco-1 }}: \operatorname{leu} A(\mathrm{G} 462 \mathrm{D})(\mathrm{EC})-$ leuBCD (EC); $\mathrm{P}_{\mathrm{Cm}}:$ cat-lacI (EC) & Connor and Liao 2008 \\
\hline
\end{tabular}

BS B. subtilis, EC E. coli, LL L. lactis, SC S. cerevisiae 
Table 3 Mutagenesis statistics for development of AL1 and AL2

\begin{tabular}{|c|c|c|c|}
\hline \multicolumn{2}{|l|}{ Mutation statistics } & \multirow{2}{*}{$\begin{array}{l}\text { Round } 1 \\
61.54 \%\end{array}$} & \multirow{2}{*}{$\frac{\text { Round } 2}{21.47 \%}$} \\
\hline Kill count & $\frac{\# \text { of NTG treated survivors }(\mathrm{LB})}{\# \text { of NTG control survivors }(\mathrm{LB})} \times 100 \%$ & & \\
\hline Frequency of mutation & $\frac{\# \text { of NTG treated mutants (M9+Analogue) }}{\text { \# of NTG treated survivors (LB) }}$ & $6.4 \times 10^{-5}$ & $1.2 \times 10^{-5}$ \\
\hline
\end{tabular}

(ampicillin $100 \mu \mathrm{g} / \mathrm{mL}$, chloroamphenicol $35 \mu \mathrm{g} / \mathrm{mL}$, and kanamycin $50 \mu \mathrm{g} / \mathrm{mL}$ ).

Detection of metabolites The produced alcohol compounds were quantified by a gas chromatograph (GC) equipped with a flame ionization detector. The system consisted of model 5890A GC (Hewlett Packard, Avondale, PA, USA) and a model 7673A automatic injector, sampler, and controller (Hewlett Packard). The separation of alcohol compounds was carried out by a DB-WAX capillary column (60 m, 0.32-mm i.d., 0.50- $\mu \mathrm{m}$ film thickness) purchased from Agilent Technologies (Santa Clara, CA, USA). GC oven temperature started at $40^{\circ} \mathrm{C}$ and was raised with a gradient of $5^{\circ} \mathrm{C} / \mathrm{min}$ until $80^{\circ} \mathrm{C}$ and held for $2 \mathrm{~min}$. It was then raised with a gradient of $45^{\circ} \mathrm{C} / \mathrm{min}$ until $125^{\circ} \mathrm{C}$ and held for $2 \mathrm{~min}$. The oven temperature was then raised at a rate of $60^{\circ} \mathrm{C} / \mathrm{min}$ until $235^{\circ} \mathrm{C}$ and held for $5 \mathrm{~min}$. Helium was used as the carrier gas with 25 -psi inlet pressure. The injector and detector were maintained at $225^{\circ} \mathrm{C}$. For aqueous samples, $0.5 \mu \mathrm{L}$ of culture broth supernatant was injected in split injection mode. For oleyl alcohol samples, samples were diluted with HPLC grade heptane in a 1:1 ratio to reduce the viscosity and increase the accuracy of injection. Glucose was quantified using a YSI 2700 SELECT Biochemistry Analyzer (YSI Life Sciences, Yellow Springs, OH, USA).

\section{Results}

Mutagenesis with NTG and selection with AZL A schematic for the mutagenesis and selection/screening process is diagrammed in Fig. 2. In order to develop a new strain for the hyperproduction of 3MB, E. coli strain JCL16 (Table 2) was treated with NTG (see "Materials and methods") and plated on minimal medium plates containing glucose $(10 \mathrm{~g} / \mathrm{L})$ and AZL (2-8 g/L). Mutants displaying resistance to AZL were re-streaked on the same minimal medium plates to validate the phenotype. Resistant strains were then screened for growth in liquid minimal medium containing AZL. Growth was quantified after $24 \mathrm{~h}$, and strains able to grow to a higher cell density were selected for transformation with kivd (Lactococcus lactis) and ADH2 (Saccharomyces cerevisiae) expressed from $\mathrm{P}_{\mathrm{L}-\mathrm{lacO} 1}$ (pIAA12; Table 2). The production of 3MB from each of these strains was quantified after $24 \mathrm{~h}$, and the strains able to produce the highest amount of $3 \mathrm{MB}$ were chosen for a final round of screening in which each of these strains was tested for $3 \mathrm{MB}$ production after overexpression of all the genes involved in the $3 \mathrm{MB}$ production pathway, including als $S$ (Bacillus subtilis), ilvCD (E. coli), leuA(G462D) (E. coli; Gusyatiner et al. 2002), and leuBCD (E. coli). These genes were all expressed from $\mathrm{P}_{\mathrm{L}-\mathrm{lacO} 1}(\mathrm{pIAA} 11$, pIAA16) along with kivd and ADH2 (pIAA13; Table 2). 3MB was quantified after 24 and $48 \mathrm{~h}$, and the mutant that produced the greatest amount of $3 \mathrm{MB}$ was chosen for further analysis.

Mutagenesis results After the first round of mutagenesis and selection with $2 \mathrm{~g} / \mathrm{L}$ of AZL, a total of 128 resistant colonies were isolated and re-streaked. Of these 128 variant strains, 21 were able to grow to at least $\mathrm{OD}_{600}=0.4$ after $24 \mathrm{~h}$ in minimal medium in the presence of $1 \mathrm{~g} / \mathrm{L}$ of AZL as cells showed an increased sensitivity to the analogue in liquid medium compared to solid medium. These mutants were transformed with kivd and $A D H 2$ (pIAA12) and assayed for $3 \mathrm{MB}$ production. Five mutants displayed a significant increase in $3 \mathrm{MB}$ production relative to parental strain $(120 \mathrm{mg} / \mathrm{L})$, and after transformation with the entire $3 \mathrm{MB}$ production pathway in these mutants, strain JCL16 NTG M8, named AL1, was able to produce nearly double the $3 \mathrm{MB}(0.75 \mathrm{~g} / \mathrm{L})$ as that of the WT $(0.43 \mathrm{~g} / \mathrm{L})$. AL1 was then selected as the parent for the next round of mutagenesis. AL1 was treated with NTG as before and selection was carried out in the presence of $8 \mathrm{~g} / \mathrm{L}$ of AZL. After the second round of mutagenesis, 64 colonies resistant to $8 \mathrm{~g} / \mathrm{L}$ of AZL on solid medium were screened for growth in liquid media with $6 \mathrm{~g} / \mathrm{L}$ of AZL, out of which 12 showed superior growth $\left(\mathrm{OD}_{600}>0.25\right)$. Six mutants outperformed the parent upon transformation of kivd and $A D H 2$ and were chosen for transformation with the entire 3MB pathway. Strain JCL16 NTG M8-C2, designated AL2, was able to produce a significantly higher amount $(1.5 \mathrm{~g} / \mathrm{L})$ of $3 \mathrm{MB}$ of that AL1 after $24 \mathrm{~h}$. AL2 was the only mutant from the second round to show an increase in $3 \mathrm{MB}$ production under this condition.

AL2 was then chosen as the parent for further mutagenesis. However, several attempts to generate a better host for $3 \mathrm{MB}$ production were unsuccessful. Strain AL2 was then compared with AL1 and JCL16 for growth, glucose consumption, and alcohol production (Fig. 3). Growth for each strain was similar, as was isobutanol production. AL1 was able to produce twice $(1.1 \mathrm{~g} / \mathrm{L})$ the $3 \mathrm{MB}$ after $72 \mathrm{~h}$ as that of JCL16 
(1)

JCL16 (WT)

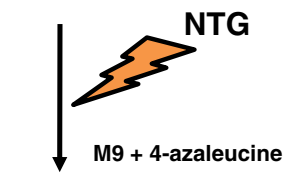

Kill Count

NTG Mutation Frequency

Spontaneous Mutation Frequency
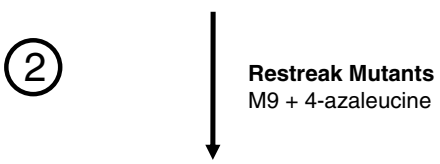

(4)

Transform with kivd-ADH2

$\mathrm{M} 9+1.0 \% \mathrm{glc}+5 \mathrm{~g} / \mathrm{L}$ YE + Trace Metals $37^{\circ} \mathrm{C} \sim 4 \mathrm{HR}:$ add $1 \mathrm{mM} \mathrm{IPTG}$ $30^{\circ} \mathrm{C} 2 \mathrm{HR}$

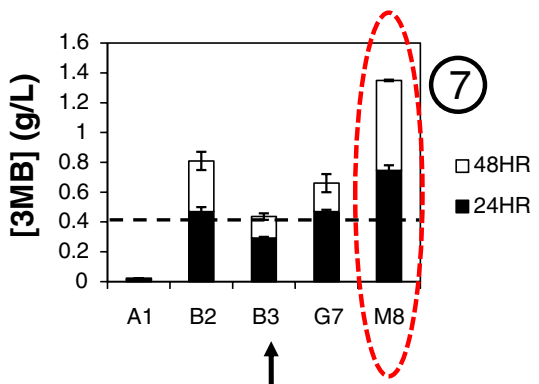

$\mathrm{M} 9+3.0 \% \mathrm{glc}+5 \mathrm{~g} / \mathrm{L}$ YE + Trace Metals

$37^{\circ} \mathrm{C} \sim 4 \mathrm{HR}$ : add $1 \mathrm{mM}$ IPTG

$30^{\circ} \mathrm{C} 44 \mathrm{HR}$

Transform with (6) 3MB Pathway

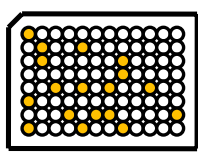

Growth Screening M9 + 4-azaleucine



Fig. 2 Diagram for mutagenesis/screening scheme. Cells are exposed to $N$-methyl- $N$ '-nitro- $N$-nitrosoguanidine and selected for resistance to 4-aza-D,L-leucine on minimal media plates. Resistant colonies are screened for growth in liquid medium in 96-well plates (3), and assayed for $3 \mathrm{MB}$ production with kivd and $A D H 2$ (5). Mutants showing an increase in production of $3 \mathrm{MB}$ are then assayed for production of $3 \mathrm{MB}$ with the entire pathway of genes (7). The highest producing mutant from this group is chosen as the parent for the next round of mutagenesis
Fig. 3 Mutant strain comparison. Growth, glucose consumption, and alcohol production was quantified in JCL16 (parent), AL1 (first round mutant), and AL2 (second round mutant) during fermentation in shake flasks. Each strain harbored plasmids pIAA11 (alsS-ilvCD) pIAA13 (kivd-ADH2), and pIAA16 (leuA (G462D)-leuBCD)
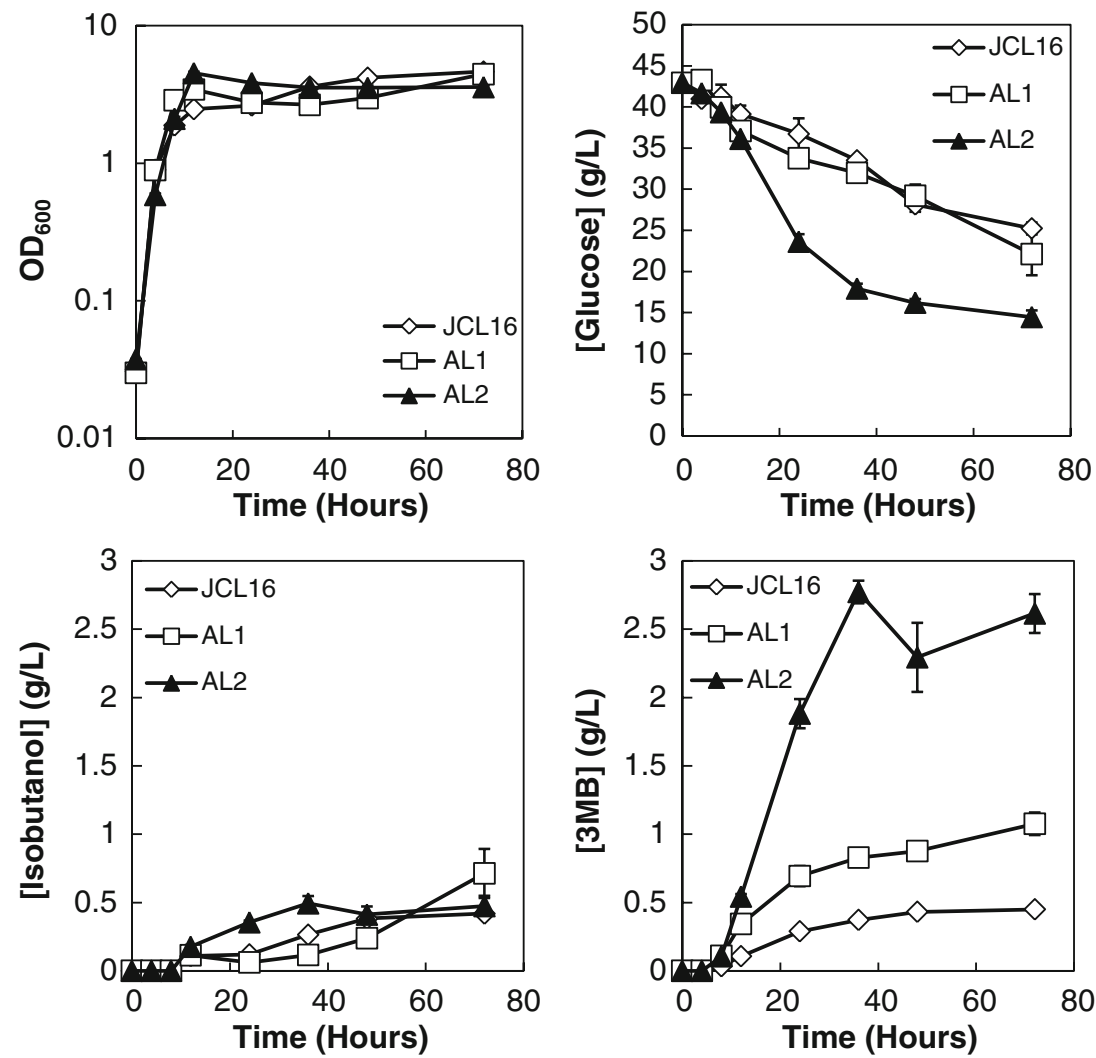

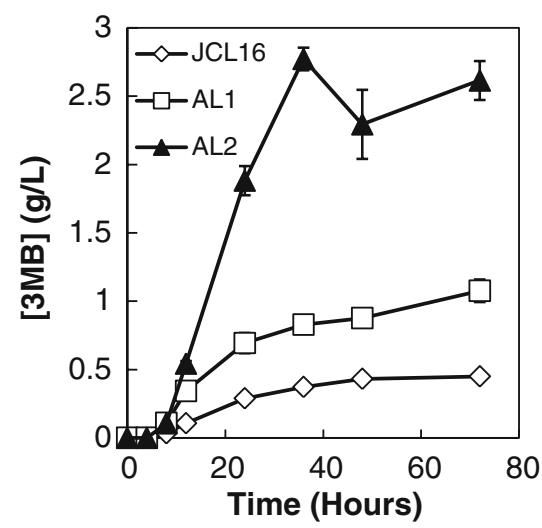


$(0.45 \mathrm{~g} / \mathrm{L})$ at a significantly higher yield $(0.08$ to $0.04 \mathrm{~g} / \mathrm{g}$ after $36 \mathrm{~h}$ ). AL2, however, showed a significant increase in glucose consumption and $3 \mathrm{MB}$ production relative to both strains. AL2 was able to produce $2.8 \mathrm{~g} / \mathrm{L}$ of $3 \mathrm{MB}$ after $36 \mathrm{~h}$ at a yield of $0.11 \mathrm{~g} / \mathrm{g}$, which is significantly higher than either parental strains in terms of final product titer and yield. After $36 \mathrm{~h}$, however, glucose consumption and $3 \mathrm{MB}$ production declined significantly.

$3 M B$ production and tolerance in $A L 2$ We hypothesized that the cessation of glucose consumption and $3 \mathrm{MB}$ production in AL2 could be due to (1) growth/medium conditions or (2) toxicity of the endogenously produced alcohol. The first hypothesis was tested using a richer medium ( $85 \mathrm{~g} / \mathrm{L}$ glucose and $10 \mathrm{~g} / \mathrm{L}$ yeast extract) to increase growth and maintaining the $\mathrm{pH}$ at 7 by the addition of $10 \mathrm{M} \mathrm{NH} \mathrm{NH}_{4} \mathrm{OH}$ as needed. The use of this medium increased growth significantly, as the $\mathrm{OD}_{600}$ was able to reach nearly 10 after just $24 \mathrm{~h}$, compared to the previous high of 4.5. The $\mathrm{pH}$ also required constant adjustment and would decrease by $\sim 1$ unit every $12 \mathrm{~h}$. After $36 \mathrm{~h}$, production reached $4.4 \mathrm{~g} / \mathrm{L}$ with a yield of $0.10 \mathrm{~g} / \mathrm{g}$
Fig. 4 Production of 3MB in AL2. a Growth, glucose consumption, and alcohol production of AL2 (second round mutant) harboring plasmids pIAA11 (als $S-i l v C D)$, pIAA13 (kivd-ADH2), and pIAA16 (leuA (G462D)leuBCD) was quantified during fermentation in shake flasks. Filled triangles represent the total $3 \mathrm{MB}$ production in AL2 fermentations containing oleyl alcohol for in situ extraction, and open triangles represent the control AL2 fermentations without oleyl alcohol. b Distribution of $3 \mathrm{MB}$ and isobutanol in oleyl alcohol fermentations. Filled bars represent the alcohol concentration in the aqueous culture, and open bars represent the alcohol concentration in the oleyl alcohol layer
A
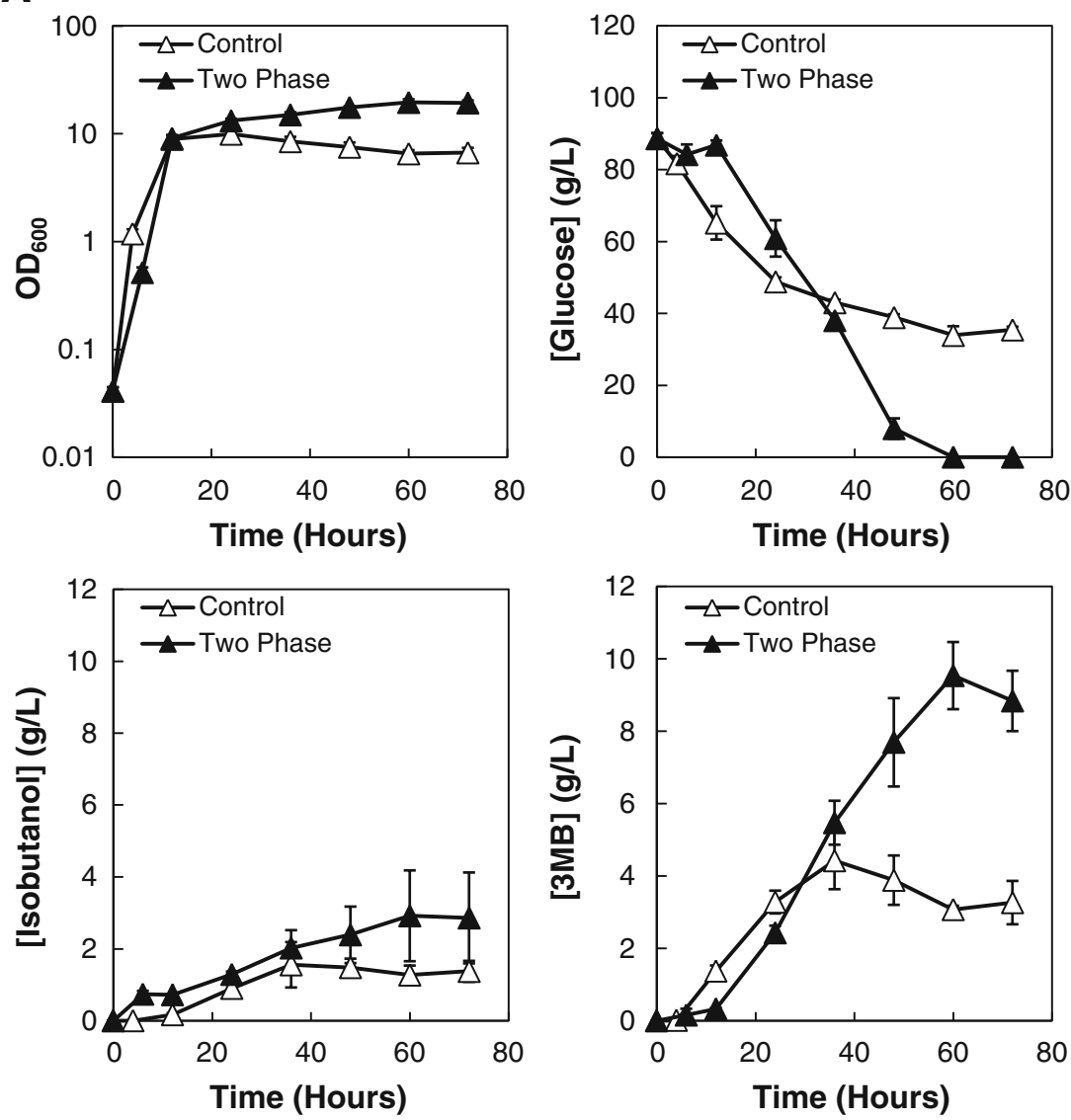

B




(Fig. 4a). Although this is a significant improvement, just as before, the consumption of glucose and production of $3 \mathrm{MB}$ declined shortly after. Next, we began to examine the second hypothesis by testing the sensitivity of AL2 to exogenously added 3MB. Various concentrations of $3 \mathrm{MB}$ (between 0 and $5 \mathrm{~g} / \mathrm{L}$ ) were added to cultures of AL2, and the cell viability was measured by counting the number of CFU at 8- and 24-h intervals. A significant growth deficiency was observed at $3 \mathrm{MB}$ concentrations as low as $1 \mathrm{~g} / \mathrm{L}$ (Fig. 5), with severe effects starting at $3 \mathrm{~g} / \mathrm{L}(<17 \%$ viability). At $5 \mathrm{~g} / \mathrm{L}$, the cell viability was less than $0.1 \%$ (Fig. 5). As expected, the toxicity of $3 \mathrm{MB}$ is far greater than that of alcohols with a shorter alkyl chain. This finding has previously been demonstrated with 1-butanol and isobutanol in which the tolerance to each of these alcohols is below $16 \mathrm{~g} / \mathrm{L}$ (Atsumi et al. 2008a; Knoshaug and Zhang 2009), which is significantly lower than that of ethanol $(\sim 50 \mathrm{~g} / \mathrm{L})$.

Two-phase fermentation These results support the hypothesis that production of $3 \mathrm{MB}$ in AL2 is limited by the toxicity of the alcohol as the cell viability at $4.4 \mathrm{~g} / \mathrm{L}$ is less than $4 \%$. To further examine this hypothesis, we employed a two-phase fermentation system to continuously remove the $3 \mathrm{MB}$ from the aqueous cellular environment. It has been shown previously that oleyl alcohol is an effective solvent for the extraction of 1-butanol during fermentation in Clostridium acetobutylicum (Roffler et al. 1987). Therefore, a volume of oleyl alcohol was added to the shake flasks equal to the culture volume at the start of fermentation, creating a two-phase system. Under these conditions, both the cell density and the glucose consumption were significantly higher than the control without oleyl alcohol, and the production of $3 \mathrm{MB}$

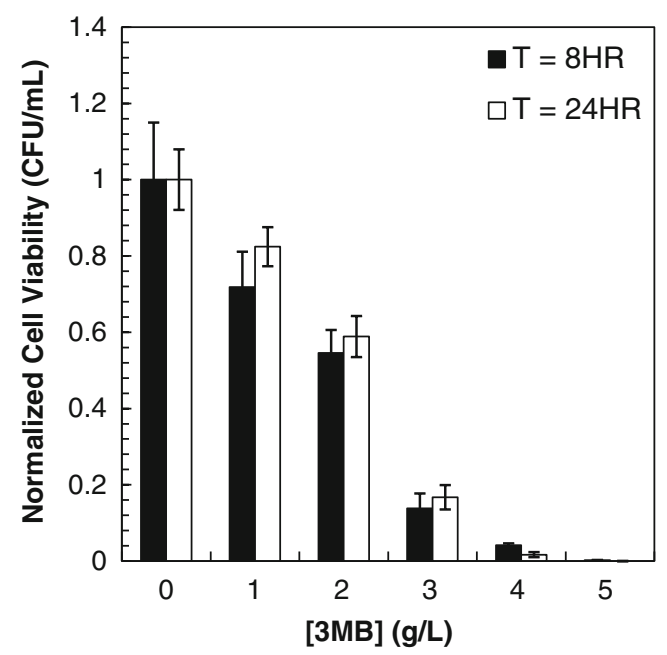

Fig. 5 Analysis of host tolerance to 3MB. Viable cell counts of AL2 after exposure to $3 \mathrm{MB}$ for 8 and $24 \mathrm{~h}$. Experiments were done with duplicate tubes and triplicate plates and normalized to the control $(0 \mathrm{~g} / \mathrm{L} 3 \mathrm{MB})$ was able to reach $9.5 \mathrm{~g} / \mathrm{L}$ after $60 \mathrm{~h}$ (Fig. $4 \mathrm{a}$ ), which is the highest production of any $\mathrm{C} 5$ alcohol yet reported in literature. The total yield for $3 \mathrm{MB}$ production from glucose was $0.11 \mathrm{~g} / \mathrm{g}$. Total alcohol production reached $12.5 \mathrm{~g} / \mathrm{L}$, which corresponds to a yield of $0.14 \mathrm{~g} / \mathrm{g}$ from glucose. Further examination shows that an average of nearly $90 \%$ of the total $3 \mathrm{MB}$ produced is contained in the oleyl alcohol layer (Fig. 4b). The maximum concentration of $3 \mathrm{MB}$ in the aqueous phase reached only $0.8 \mathrm{~g} / \mathrm{L}$, at which the cell viability is greater than $70 \%$ (Fig. 5). The oleyl alcohol was also able to extract an average of over $81 \%$ of the total isobutanol produced, demonstrating that this may be an effective strategy for the extraction of other higher chain alcohols. These results clearly demonstrate that the production of $3 \mathrm{MB}$ in $\mathrm{AL} 2$ greatly benefits from using a continuous extractive process as the toxicity barrier can be avoided to significantly increase production levels to greater than $5 \mathrm{~g} / \mathrm{L}$.

\section{Discussion}

A major advantage in the engineering of higher chain alcohol production is the implementation of existing amino acid technologies for process improvement. Of these many technologies, random whole cell mutagenesis and selection with amino acid analogues (Table 1), in particular, has been widely used to develop biocatalysts for the production of many amino acids such as L-threonine, L-isoleucine, L-valine, and L-leucine among many others (Ikeda 2003). Here, we applied this strategy for the development of a strain of $E$. coli for the production of 3-methyl-1-butanol by selecting for resistance to a L-leucine analogue and screening for increased $3 \mathrm{MB}$ production. This strategy is advantageous over rational engineering approaches in that it requires minimal knowledge of the metabolic pathway, and because selective pressure is being used, a large library of mutants can be generated to cover a much more significant portion of sequence space to generate the desired phenotype. Two successive rounds of mutagenesis and selection with AZL resulted in a strain (AL2) able to produce $4.4 \mathrm{~g} / \mathrm{L}$ of $3 \mathrm{MB}$. This strategy of random mutagenesis and selection can also be used to develop strains for the production of other higher chain alcohols such as isobutanol (L-valine), 1-propanol (L-threonine), 2-methyl-1-butanol (L-isoleucine), and phenylethanol (L-phenylalanine). Furthermore, many of these processes can be challenged with several different analogues in succession, resulting in superior productivity, as oftentimes, many different structural analogues are available for a single amino acid (Table 1). This is also applicable in cases where other amino acids serve as precursors to the final amino acid of interest. For example, 2-methyl-1-butanol is synthesized 
from an L-isoleucine precursor which itself is synthesized from L-threonine. Therefore, a strain can be developed using structural analogues for both L-threonine ( $\alpha$-amino- $\beta$ hydroxyvaleric acid) and L-isoleucine (D,L-4-thiaisoleucine; Table 1).

Analysis of the host tolerance to $3 \mathrm{MB}$ revealed that the productivity in this strain may be limited by the host's sensitivity to the product. The viability of AL2 at $4.4 \mathrm{~g} / \mathrm{L}$ of $3 \mathrm{MB}$ was found to be less than $4 \%$, suggesting that the toxicity of the product is limiting its own production and growth. A two-phase fermentation with oleyl alcohol allowed for a prolonged production phase in which $3 \mathrm{MB}$ was able to reach a total of $9.5 \mathrm{~g} / \mathrm{L}$ after $60 \mathrm{~h}$ with a yield of $0.11 \mathrm{~g} / \mathrm{g}$, with nearly $90 \%$ of the $3 \mathrm{MB}$ contained within the oleyl alcohol. The yield of this experiment is $33 \%$ of the theoretical maximum $(0.33 \mathrm{~g} / \mathrm{g})$, which is calculated from a stoichiometric balance from glucose to $3 \mathrm{MB}$ under the assumption that excess reducing power in the form of $\mathrm{NAD}(\mathrm{P}) \mathrm{H}$ can be recycled to $\mathrm{NAD}(\mathrm{P})^{+}$by $\mathrm{O}_{2}$. Total alcohol production reached $12.5 \mathrm{~g} / \mathrm{L}$. The success of this approach increases the potential of producing $3 \mathrm{MB}$ as a biofuel from $E$. coli as titers can potentially reach in excess of $30 \mathrm{~g} / \mathrm{L}$ before the aqueous concentration of $3 \mathrm{MB}$ again becomes troublesome.

This work also demonstrates the utility and potential in using E. coli as a host for biofuel production. The accumulated wealth of knowledge and developed genetic tools, as well as previous successes in pathway engineering and metabolite production (Chao et al. 1993; Farmer and Liao 2001; Martin et al. 2003) as well as amino acid production (Ikeda 2003), make E. coli an attractive host for higher chain alcohol production via the 2-keto acid pathways. As production titers continue to increase, existing tools and technology for product removal (Roffler et al. 1987) and increasing host solvent tolerance (Alper et al. 2006; Atsumi et al. 2008a; Borden and Papoutsakis 2007; Yomano et al. 1998), along with the elucidation of solvent response pathways (Brynildsen and Liao 2009; Tomas et al. 2004), can be applied to maintain the development of these processes.

Acknowledgments We would also like to thank the UCLA-DOE Joint Genome Institute and Gevo, Inc. for providing funding for this work.

Open Access This article is distributed under the terms of the Creative Commons Attribution Noncommercial License which permits any noncommercial use, distribution, and reproduction in any medium, provided the original author(s) and source are credited.

\section{References}

Alper H, Moxley J, Nevoigt E, Fink GR, Stephanopoulos G (2006) Engineering yeast transcription machinery for improved ethanol tolerance and production. Science 314:1565-1568
Atsumi S, Liao JC (2008) Metabolic engineering for advanced biofuels production from Escherichia coli. Curr Opin Biotechnol 19:414-419

Atsumi S, Hanai T, Liao JC (2008a) Non-fermentative pathways for synthesis of branched-chain higher alcohols as biofuels. Nature 451:86-89

Atsumi S, Cann AF, Connor MR, Shen CR, Smith KM, Brynildsen MP, Chou KJ, Hanai T, Liao JC (2008b) Metabolic engineering of Escherichia coli for 1-butanol production. Metab Eng 10:305311

Borden JR, Papoutsakis ET (2007) Dynamics of genomic-library enrichment and identification of solvent tolerance genes for Clostridium acetobutylicum. Appl Environ Microbiol 73:30613068

Brynildsen MP, Liao JC (2009) An integrated network approach identifies the isobutanol response network of Escherichia coli. Mol Syst Biol 5:277

Cann AF, Liao JC (2008) Production of 2-methyl-1-butanol in engineered Escherichia coli. Appl Microbiol Biotechnol 81:8998

Chao YP, Patnaik R, Roof WD, Young RF, Liao JC (1993) Control of gluconeogenic growth by pps and pck in Escherichia coli. J Bacteriol 175:6939-6944

Connor MR, Liao JC (2008) Engineering of an Escherichia coli strain for the production of 3-methyl-1-butanol. Appl Environ Microbiol 74:5769-5775

Connor MR, Liao JC (2009) Microbial production of advanced transportation fuels in non-natural hosts. Curr Opin Biotechnol 20:307-315

Dinneen B (2008) Changing the climate: Ethanol Industry Outlook 2008. In: RFA outlook. Renewable Fuels Association. http:// www.ethanolrfa.org/objects/pdf/outlook/RFA_Outlook_2008.pdf. Accessed October 6, 2009

Farmer WR, Liao JC (2001) Precursor balancing for metabolic engineering of lycopene production in Escherichia coli. Biotechnol Prog 17:57-61

Gusyatiner MM, Lunts MG, Kozlov YI, Ivanovskaya LV, Voroshilova EB (2002) DNA coding for mutant isopropylmalate synthase L-leucine-producing microorganism and method for producing L-leucine. United States Patent 6,403,342

Ikeda M (2003) Amino acid production processes. In: Scheper T (ed) Advances in biochemical engineering/technology. Springer, Berlin, pp 1-35

Kim Y, Ingram LO, Shanmugam KT (2007) Construction of an Escherichia coli K-12 mutant for homoethanologenic fermentation of glucose or xylose without foreign genes. Appl Environ Microbiol 73:1766-1771

Knoshaug EP, Zhang M (2009) Butanol tolerance in a selection of microorganisms. Appl Biochem Biotechnol 153:13-20

Lee SY, Park JH, Jang SH, Nielsen LK, Kim J, Jung KS (2008) Fermentative butanol production by Clostridia. Biotechnol Bioeng 101:209-228

Lee JY, Jang YS, Lee J, Papoutsakis ET, Lee SY (2009) Metabolic engineering of Clostridium acetobutylicum M5 for highly selective butanol production. Biotechnol J 4:1432-1440

Martin VJ, Pitera DJ, Withers ST, Newman JD, Keasling JD (2003) Engineering a mevalonate pathway in Escherichia coli for production of terpenoids. Nat Biotechnol 21:796-802

Miller JH (1972) Experiments in molecular genetics. Cold Spring Harbor Laboratory, Cold Spring Harbor

Roffler SR, Blanch HW, Wilke CR (1987) In-situ recovery of butanol during fermentation. Bioprocess Biosyst Eng 2:1-12

Seiferlein KE (2009) Annual energy review 2008. In: Annual energy review. Energy Information Administration. http:// www.eia.doe.gov/emeu/aer/contents.html. Accessed October 6, 2009 
Shen CR, Liao JC (2008) Metabolic engineering of Escherichia coli for 1-butanol and 1-propanol production via the keto-acid pathways. Metab Eng 10:312-320

Stephanopoulos G (2007) Challenges in engineering microbes for biofuels production. Science 315:801-804

Tomas CA, Beamish J, Papoutsakis ET (2004) Transcriptional analysis of butanol stress and tolerance in Clostridium acetobutylicum. J Bacteriol 186:2006-2018

Withers ST, Gottlieb SS, Lieu B, Newman JD, Keasling JD (2007) Identification of isopentenol biosynthetic genes from Bacillus subtilis by a screening method based on isoprenoid precursor toxicity. Appl Environ Microbiol 73: $6277-6283$

Yan Y, Liao JC (2009) Engineering metabolic systems for production of advanced fuels. J Ind Microbiol Biotechnol $36: 471-479$

Yomano LP, York SW, Ingram LO (1998) Isolation and characterization of ethanol-tolerant mutants of Escherichia coli KO11 for fuel ethanol production. J Ind Microbiol Biotechnol 20:132-138

Zhang K, Sawaya MR, Eisenberg DS, Liao JC (2008) Expanding metabolism for biosynthesis of nonnatural alcohols. Proc Natl Acad Sci U S A 105:20653-20658 